\title{
Iniciativas
}

\section{La vida en la residencia del CRE de Madrid en tiempos de la covid-19}

\section{Gutiérrez de Rave Aguera, P. Iglesias Junco, M. M. Jiménez Palazón, A. Torres Torres}

«Estamos en crisis y hay una enfermedad» (una alumna).

La vida cotidiana del alumnado del Centro de Recursos Educativos (CRE) ${ }^{1}$ de Madrid transcurre con importantes cambios, como en el resto de la sociedad. La mayoría, por estar sus domicilios lejanos, son residentes. La residencia es el lugar donde viven durante el curso escolar, y la covid-19 ha modificado sustancialmente sus rutinas. Nos reunimos con ellos para que nos cuenten cómo les afectan estas novedades y reflexionen sobre sus nuevas vivencias. Esto es lo que nos han contado.

Figura 1. Educadora le toma la temperatura a una alumna

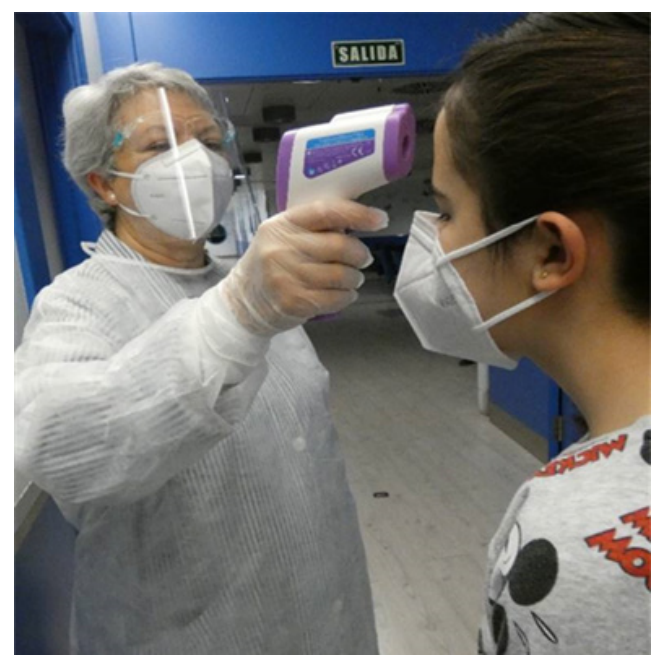

\footnotetext{
1 EI CRE de la ONCE en Madrid atiende a los alumnos que presentan necesidades educativas especiales derivadas de la discapacidad visual y de la sordoceguera. Cuenta, además, con centro escolar y servicio de residencia para alumnos de educación primaria, secundaria obligatoria y educación especial de niños con sordoceguera.
} 
Aún es de noche cuando se incorpora el primer turno de trabajo, el reloj apenas marca las siete de la mañana. Entrando, a mano izquierda, cuatro puertas de cristal traslúcido avisan con cuatro carteles de «Prohibido el paso». Solo el personal indispensable puede entrar en el área de residencia; es una burbuja de convivencia, se minimizan los contactos externos. Los educadores preparan sus EPI (mascarillas FPP2, pantallas faciales, guantes, batas especiales) y se dirigen a despertar a su grupo. A las 7.15 se toca diana y comienza la actividad cotidiana.

\section{Empezamos el día}

Un largo pasillo da acceso a todos los dormitorios que se encuentran en la segunda planta. La frenética actividad se inicia: levantarse, aseo, orden, llevar la ropa sucia a la lavandería, subir y guardar la limpia, desayunos...

«Cuando te despiertas, por la mañana, viene una educadora diciendo "iTemperatuuraaaa!". Estás durmiendo tan panchamente y te encuentras el termómetro en la frente: ipi! ipi!», comenta Belén, ${ }^{2}$ una alumna de secundaria.

Su compañera Nadia añade: «Te impresiona que te levanten y te tengan que tomar todos los días la temperatura».

«Al levantarme, lo primero que hago es quitar la calefacción y abrir la ventana, no me vaya a subir la temperatura y me confinen. También nos la toman por la noche» (Irene).

«Una se acostumbra a que le pongan el termómetro» (Carla).

«A mí una vez me dio hipotermia»(Rosa).

\section{Prevenimos en el comedor}

Es un lugar delicado, aquí necesitan quitarse la mascarilla; la distancia y el seguimiento de normas son fundamentales. Antes comían en mesas compartidas, ahora no; son mesas separadas a la distancia recomendable unas de otras. Toda la comida sale de la cocina en platos individuales, directamente a cada destinatario. El personal que les atiende extrema medidas en contactos y manipulaciones. Aun así, los educadores y el alumnado necesitan establecer contacto físico para conseguir la adquisición de las habilidades de autonomía personal necesarias.

2 Todos los nombres propios que hacen referencia al alumnado en este artículo son ficticios (N. del E.).

Gutiérrez de Rave, M., Iglesias, P., Jiménez, M. M., y Torres, A. (2021). La vida en la residencia del CRE de Madrid en tiempos de la covid-19. RED Visual: Revista Especializada en Discapacidad Visual, 77, 327-336. https://doi.org/10.53094/XNZL2821. 
«Antes comíamos todos juntos y ahora estamos en una mesa individual; dificulta mucho hablar entre nosotros» (Nadia).

«Todo el tiempo la mascarilla, pero cuando comes tienes que quitártela» (Arturo).

«Cuando queremos hablar no podemos como antes. Te metes una cucharada en la boca $y$, si quieres hablar, hay que ponerse la mascarilla, y si no, vienen los educadores a recordártelo» (Belén).

\section{Un tiempo libre distinto}

Es quizá lo más duro para ellos. Ya han vivido un confinamiento largo en sus casas y ahora necesitamos que la burbuja continúe. La zona básica de salud Vandel (en Moratalaz, nuestro distrito), a la que pertenecemos, ha tenido incidencias altas sufriendo restricciones perimetrales. Otros años eran habituales salidas de fin de semana por distintos lugares de la ciudad: visitas culturales, ocio, restauración, espectáculos, etc. Este curso ha sido menos movido. Los recursos de juego se han controlado para seguir recomendaciones sanitarias.

Para Arturo «Cada vez salimos menos los fines de semana; no podemos ir al cine, a comprar chuches, se hace pocas veces».

«En las salidas, al ir por la calle, hay menos personas que antes; las pocas que hay llevan mascarilla y guardan distancia» (Mario).

«He notado que ya no podemos ir a los bares», lamenta Jorge.

«Ahora solo podemos salir poca gente y a sitios al aire libre, y si el grupo es más grande, tienen que salir muchos educadores» (Belén).

«Antes, cuando salías, veías a un chico o chica y le decías: ioye, perdona!, ¿tu instagram?, y ahora no puedes; no me dejan socializarme, no puedo acercarme, ahora llevan mascarilla..., ahora ¿cómo veo si esa persona es guapa?» (Nadia).

«Ya no podemos ni coger transporte público, ni sitios cerrados; es un agobio, solo coger el taxi y ya está, para ir al aeropuerto y poco más» (Rosa).

«Las salidas que hacemos el fin de semana son muy pocas. Antes podíamos ir al burger, a tomar un helado, que nos gusta mucho, o a comprar una bolsa de patatas. Esas cosas es como que se han perdido» (Irene).

«En el tiempo libre no podemos jugar con los columpios. Cuando jugamos a fútbol, con la mascarilla, cuesta un poco más respirar» (Ander).

«Echo de menos los columpios» (Jorge).

Gutiérrez de Rave, M., Iglesias, P., Jiménez, M. M., y Torres, A. (2021). La vida en la residencia del CRE de Madrid en tiempos de la covid-19. RED Visual: Revista Especializada en Discapacidad Visual, 77, 327-336. https://doi.org/10.53094/XNZL2821. 
«En deporte te cuesta más, te cansas más rápido, tienes miedo a que algún amigo coja el covid» (Bernat).

«Cada vez que cogen un juguete o balón hay que desinfectarlo. No se pueden coger muchos a la vez. Son muy pesados; todo el día desinfectando los juguetes, todo el día, todo el día. En la pizarra dice: "Hay que desinfectar los juguetes"» (Manu).

«En la hora del recreo queremos estar todos en una sala, pero no podemos por el límite de aforo» (Rosa).

«La tele no la podemos ver juntos, tenemos que estar es espacios separados» (Irene).

«El día que fuimos a Faunia solo pude tocar a las ovejas, las cabras, al burro y al poni» (Carla).

\section{Nuestras relaciones}

Si la vida residencial se caracteriza por algo es por las fuertes y constantes relaciones entre jóvenes; convivir intensamente crea vínculos. Entre el grupo, el contacto físico es fundamental, y esta necesidad se acentúa cuando llega la adolescencia. Tener que limitar este tipo de contactos dificulta cubrir esas necesidades. Contacto sí, pero con cabeza.

«En la relación con compañeras, lo que peor llevamos es no poder estar con ellas en la habitación, no poder darnos abrazos» (Belén).

«Echo en falta no poder dar un abrazo a mis compañeros, amigos, no poder veros las caras a todos vosotros. Para un deficiente visual le dificulta la vida diaria no poder tener contacto con otras personas» (Mario).

«Me afecta no tener la misma relación con compañeros y trabajadores por la distancia. Un compañero necesita ayuda y no puedes acercarte todo lo necesario para poder ayudarle lo suficiente. Cuando estás con ellos hablando, divirtiéndote, antes veías la cara de esa persona, pero ahora no se si está riéndose, está llorando o está mal. Se nos dificulta un poco ver las expresiones de la cara» (Nadia).

«Eso de mantener la distancia no me gusta nada, no poder abrazarnos y darnos un beso, el sentarnos juntos; ojalá se pueda hacer» (Olga).

«Antes podíamos estar tres o cuatro apiñados en el sofá y ahora no podemos» (Nadia).

Solo hemos tenido dos sustos con dos compañeros, pero nada más» (Bernat).

«Las personas que no oyen bien, pero sí ven algo, por mucho que les hables en lengua de signos, si tú no vocalizas, les cuesta comprenderte, no ven tu expresión» (Belén).

Gutiérrez de Rave, M., Iglesias, P., Jiménez, M. M., y Torres, A. (2021). La vida en la residencia del CRE de Madrid en tiempos de la covid-19. RED Visual: Revista Especializada en Discapacidad Visual, 77, 327-336. https://doi.org/10.53094/XNZL2821. 
«Conocí a gente de la ONCE durante el confinamiento, porque estuvieron más en redes sociales» (Rosa).

«Las cuatro semanas que estuve sin salir se hicieron largas; sin poder irme a casa, tuve sensación de agobio. Ya no puedo ir cada dos semanas por esto del covid. Es para protegernos, porque en los aviones no puede mantenerse la distancia» (Jorge).

«Cuando vamos a casa y voy en transporte público, debo tener muchísimo cuidado por mi abuela; te duele no poder acercarte a tu familiar» (Nadia).

«Yo vivo al lado de mis abuelos y me voy a comer con ellos muchas veces. Vengo de un colegio donde hay muchas personas. Me da miedo por ellos, por mis padres, por mi hermano. Soy persona de riesgo y me preocupo más por pegárselo a alguien que porque lo pase yo» (Irene).

\section{Todos con mascarilla}

Otra prueba dura para el grupo es llevar constantemente la mascarilla. Fundamentalmente utilizan la quirúrgica y, salvo momentos concretos (habitación, comedor, piscina...), la llevan constantemente.

«Es un poco molesto lo de las mascarillas; me la pongo bien. A veces, se me olvida cogerla. Cada poco tengo que subirla porque se sale la nariz» (Jorge).

«No me gusta llevar una mascarilla, dificulta respirar, casi no te deja. Se tira dinero; las usas y las tiras, las usas y las tiras» (Manu).

«Ya no te das cuenta si te la pones del derecho o del revés; te vas a peinar... iuy!, si la tengo del revés» (Nadia, Belén).

«No veo bien cuál es la parte de azul y blanca y a veces la pongo al revés, hasta que me lo dicen: lo de fuera "pa" dentro» (Rosa).

«Un día salía de natación y, sin querer, casi me voy sin mascarilla, "iuy!, es verdad, que tengo que ponerme la mascarilla"» (Olga).

«Tienes que repetir dos o tres veces las cosas para que te entiendan» (Nadia).

«Al principio de curso bajé hasta el sótano sin mascarilla y nadie se dio cuenta» (Dioni).

«Despistes a la hora de ponérsela. Con la mascarilla proyectas menos la voz» (Belén).

«Al principio, cuando llegué, era muy incómodo; estaba acostumbrada a estar en casa sin ella. Muchas veces salía de la habitación, no la llevaba, me daba cuenta y tenía que volver a por ella. Al final, te acostumbras» (Irene).

«Me molesta en las orejas» (Carla).

Gutiérrez de Rave, M., Iglesias, P., Jiménez, M. M., y Torres, A. (2021). La vida en la residencia del CRE de Madrid en tiempos de la covid-19. RED Visual: Revista Especializada en Discapacidad Visual, 77, 327-336. https://doi.org/10.53094/XNZL2821. 


\section{Las pruebas de antígenos}

Cuando llegan de sus casas de fin de semana, puentes, etc., o si el Centro lo considera necesario, se realizan test de antígenos. El personal sanitario recoge una muestra de la nariz y se analiza al instante; en 15 minutos se obtienen resultados.

«Cuando regresas de casa, te hacen pruebas y es bastante molesto, la verdad» (Arturo). «La última vez creo que le rompí la bata a la pobre enfermera; me ponía nervioso y no dejaba que me agarraran. Al final me la hicieron; no sé cómo, pero me la hicieron. Cuando entraba el palo ese [bastoncillo por la nariz], me quitaba, movía la cabeza, no me dejaba agarrar. Acabó bien» (Jorge). La insistencia de aquella enfermera que no se iba de allí sin hacer la prueba...

«A mí me hicieron cosquillas» (Andreu).

«Me alegro de que nos las hayan hecho con el palito por la nariz y no por aguja; me da miedo» (Rosa).

«Las dos chicas que vinieron de la Cruz Roja, las mejores, fueron delicadas; no te hacían ningún daño, y decían: "Ya está". iHala, "pa" tu casa! Y tan tranquila, o sea, ya te ibas otra vez a clase» (Nadia).

«Las de la Cruz Roja me decían que no me iban a hacer daño. Lo hacían suave, lo dijeron para que no me sintiera mal. Empiezo a notar un líquido, como que con el palo me sacaba una cosa» (Olga).

«Te sacan un moco del fondo de la nariz, me lo dijo mi madre» (Manu).

«Al principio bien, pero ahora debo tener resentida la nariz y cada vez que me meten el palito me duele un montón. Como nos lo hacen cada poco, pues lo llevo muy mal» (Irene).

«Creo que no me voy a acostumbrar en la vida a eso de que me metan un palo por la nariz» (Carla).

\section{Algunos tuvieron que confinarse en el Centro}

En ocasiones, han saltado las alarmas: contactos estrechos con positivos, temperatura corporal alta... Entonces se siguen protocolos de prevención para evitar posibles brotes internos. No queda otra, hay que aislar.

«Raro, cuando me confinaron en el cole, es muy raro. La mascarilla por todos los sitios» (Manu).

Gutiérrez de Rave, M., Iglesias, P., Jiménez, M. M., y Torres, A. (2021). La vida en la residencia del CRE de Madrid en tiempos de la covid-19. RED Visual: Revista Especializada en Discapacidad Visual, 77, 327-336. https://doi.org/10.53094/XNZL2821. 
«Me pareció muy mal estar aislado, sentí soledad, estaba triste por estar solo; cuesta aguantar, lloraba y tenía que llamar a mi madre y a mi abuela» (Andreu).

«Si estás confinado, pues tienes que estar solo; da pena ver a un compañero así» (Irene).

\section{Las manos siempre limpias}

La higiene general y la de manos, en particular, han sido constantes. Geles hidroalcohólicos, desinfectantes de superficies, dispensadores en la mayoría de los espacios..., virus bajo control.

«Los geles son muy asquerosos, muy pegajosos; unos huelen bien y otros no tanto» (Manu).

«Echarse todo el rato gel hidroalcohólico. Hay que echarse cada dos por tres geles hidroalcohólicos» (Bernat).

«Al final estamos todo el día juntos y somos gente que no vemos bien. Quieras que no, acabas tocando cosas, se te olvida echarte gel y, al final, va otra, la toca y puede haber contagios. Ya no se puede tocar nada, no sabes quién ha tocado antes, hay que andar con mucho cuidado» (Irene).

«Agradecería que no fuese tan pegajoso» (Andreu).

\section{Ventilación de espacios}

Compartir espacios requiere renovar el aire con frecuencia; el tiempo, a veces, no acompaña.

«Si abrís tanto las ventanas, no vamos a enfermar por covid: vamos a enfermar por pulmonía» (Dioni).

«Pasamos frio por no poder juntarnos los compañeros. Debemos tener ventilación constantemente, las ventanas abiertas todo el santo día. A veces tienes ganas de ir con una manta. Antes iba en manga corta, ahora voy en manga larga» (Nadia).

\section{Sentimientos}

Se dice que el miedo es libre; pero, a veces, lo tienes tan dentro que no se puede liberar. Momentos, situaciones, experiencias, informaciones que nos producen eso...

Gutiérrez de Rave, M., Iglesias, P., Jiménez, M. M., y Torres, A. (2021). La vida en la residencia del CRE de Madrid en tiempos de la covid-19. RED Visual: Revista Especializada en Discapacidad Visual, 77, 327-336. https://doi.org/10.53094/XNZL2821. 
«Sentí miedo cuando algún adulto estuvo afectado» (Arturo).

«La tele acaba metiendo miedo de todas las cosas que pasan. El estar aquí, hasta que llega un puente y te puedes ir a casa, cuesta mucho» (Irene).

«Cuando subo al tren y tengo que cogerme a la barandilla, siento miedo; no me agarro por si acaso. Pienso que me puedo caer, y mi padre me dice que dé un paso largo, hacia arriba y ya está» (Bernat).

\section{Algunas cosas cambiaron}

Grandes cambios, pequeños cambios, a veces solo diminutos matices, pero sí, las cosas cambiaron.

«Antes estaba con gente en la habitación, ahora estás solo. A veces te apetece estar con un compañero y charlar, ahora con las mascarillas es algo que molesta. Estar un mes encerrado no ayuda» (Dioni).

«Sobre todo no poder salir del Centro, tanto a casa como a hacer actividades» (Belén).

«El año pasado a alguien le gustaba una camiseta tuya y se la dejabas, este no se puede hacer, aunque hayas dado negativo no sabes» (Paula).

«Hay personas ciegas o con baja visión a las que antes se las ayudaba más; no sé si por miedo o por qué, pero ahora la gente se ha distanciado mucho» (Irene).

«Al principio, me costó acostumbrarme a la distancia de seguridad. Fui a ver a mi prima y notaba que no se acercaba a mí. Ya estoy acostumbrada a que la gente mantenga la distancia» (Carla).

«Este año no hubo las jornadas lúdicas y deportivas que antes se realizaban» (Arturo). «Eché de menos no poder hacer campamentos en verano» (Andreu).

«La gente compra por Amazon en lugar de en las tiendas» (Rosa).

«En el CRE no hay muchas dificultades, pero fuera sí; aquí la gente comprende que no vemos y tenemos que tocar» (Manu).

\section{Los educadores acompañan en las dinámicas cotidianas}

No solo es intensa la convivencia entre iguales. El personal de residencia acompaña sus rutinas del día a día y esta es su percepción.

Gutiérrez de Rave, M., Iglesias, P., Jiménez, M. M., y Torres, A. (2021). La vida en la residencia del CRE de Madrid en tiempos de la covid-19. RED Visual: Revista Especializada en Discapacidad Visual, 77, 327-336. https://doi.org/10.53094/XNZL2821. 
«A los educadores les toman la temperatura al entrar. Nos daría pena que se contagiasen. Algo están haciendo bien, las cosas están resultando bien. Parecen a los de las centrales nucleares. No hemos tenido ningún contagio» (Nadia).

«Van con bata y mascarillas, una pantalla toda rara, a mí me da hasta miedo, son "to" feas. Van muy protegidos»(Dioni).

«Hay educadores que no les recuerdo sin mascarilla»(Paula).

«A veces oigo a la educadora como si estuviese dentro de una pecera, pero es porque lleva pantalla» (Carla).

«Siempre están diciendo "ila distanciiiaaa!"; están todos más pesados, más gruñones, muy plastas» (Manu).

«Ahora están como más encima, más vigilantes, que no nos juntemos, que no haya más roces...» (Irene).

\section{Entienden las normas establecidas}

Se crea cierto debate sobre la aplicación de las medidas preventivas que podemos resumir en dos aportaciones.

«Las educadoras nos están advirtiendo de las distancias de seguridad, hay demasiada gente en los hospitales. Lo están haciendo para que no te contagies» (Dioni).

«Es seguridad para ellos y para nosotros. Yo entiendo que estén más encima» (Irene).

«Hasta la fecha estáis cumpliendo las normas, estáis echando gel, os ponéis las mascarillas. Está resultando, no tuvimos contagios. Por vuestro lado, estáis cumpliendo muy bien, lo estáis haciendo fenomenal», añade una educadora.

\section{Llega la noche}

El día concluye, es momento de recogerse. Al no compartir dormitorios, no pueden quedarse hablando de sus cosas. La segunda planta se va quedando silenciosa, el bullicio de la tarde se desvanece a medida que se van cerrando las puertas de sus habitaciones. Mañana será otro día, pero seguiremos igual, en alerta.

«El peor momento del día es cuando nos vamos a dormir. Antes nos abrazábamos, un beso de buenas noches, te sentías un poco arropada por tus compañeros. Nos dábamos las buenas noches e ibas tan feliz a la cama. Ahora me siento un poco rara, sin poder dar un beso a mi amiga y decirle "buenas noches"», comenta Nadia.

Gutiérrez de Rave, M., Iglesias, P., Jiménez, M. M., y Torres, A. (2021). La vida en la residencia del CRE de Madrid en tiempos de la covid-19. RED Visual: Revista Especializada en Discapacidad Visual, 77, 327-336. https://doi.org/10.53094/XNZL2821. 
«Por la noche, algunas personas duermen solas; no tener a nadie en la habitación es más difícil, se echa de menos la compañía» (Rosa).

«No estar con nadie en la habitación es triste» (Paula).

«La verdad, me gusta más estar sola en la habitación» (Ana).

«Al estar solos, se duermen pronto» (educador de noche).

Las palabras que más han sonado este curso, por consenso del grupo, son: «covid», «coronavirus», «termómetro», «ventilación», «mascarillas», «gel hidroalcohólico».

Manuel Gutiérrez de Rave Aguera. Cuidador-educador. Servicio de Residencia. Centro de Recursos Educativos de la ONCE en Madrid. Avenida del Doctor García Tapia, 210; 28030 Madrid (España). Correo electrónico: mgagu@once.es.

Pablo Iglesias Junco. Cuidador-educador. Servicio de Residencia. Centro de Recursos Educativos de la ONCE en Madrid. Avenida del Doctor García Tapia, 210; 28030 Madrid (España). Correo electrónico: pij@once.es.

María del Mar Jiménez Palazón. Cuidadora-educadora. Servicio de Residencia. Centro de Recursos Educativos de la ONCE en Madrid. Avenida del Doctor García Tapia, 210; 28030 Madrid (España).Correo electrónico: mjpal@once.es.

Antonia Torres Torres. Cuidadora-educadora. Servicio de Residencia. Centro de Recursos Educativos de la ONCE en Madrid. Avenida del Doctor García Tapia, 210; 28030 Madrid (España). Correo electrónico: atto@once.es.

Gutiérrez de Rave, M., Iglesias, P., Jiménez, M. M., y Torres, A. (2021). La vida en la residencia del CRE de Madrid en tiempos de la covid-19. RED Visual: Revista Especializada en Discapacidad Visual, 77, 327-336. https://doi.org/10.53094/XNZL2821. 